\title{
A Survey Study of Factors on Multilingual Attitude of College Students in Minority Areas
}

\author{
Yujie Shi \\ Yanbian University, Yanji, Jilin Province, China \\ Xuebo Cui \\ Yanbian University, Yanji, Jilin Province, China
}

\begin{abstract}
Positive attitude and motivation are often mentioned as necessary for language learning and the development of positive attitude is often seen as one of the aims of teaching languages. To know what attitudes are like in multilingual educational environment and status of different languages is important. This study takes college students from Yanbian Korean Autonomous Prefecture as the research subject, uses quantitative research and qualitative research to investigate the situation of multilingual attitude and discuss gender, grade, major, ethnicity and other factors on language attitude. The results show that gender, grade, major and ethnicity all influence students' language attitude in different degrees. Based on the results and the current situation of language education for college students in minority areas, this paper tries to put forward some suggestions on multilingual education in minority areas in order to contribute to the construction of multilingual, multi-cultural and harmonious language living environment.
\end{abstract}

Index Terms - multilingual attitude, factors, minority areas

\section{INTRODUCTION}

As the key content of language life, language attitude has always been one of the hot issues in sociolinguistics. The study of language attitude has important practical significance and value for understanding the psychological characteristics of individuals, groups or nations. At the same time, the study of language attitude can provide reference information for language education to improve the quality of bilingual and multilingual teaching. Bilingual education expert Baker (1992) believed that language attitude of language learners had an important impact on the effectiveness of language learning in bilingual education. It is particularly important to pay attention to the language attitude of individuals and ethnic groups toward their mother tongue, Chinese language and other foreign languages. In the bilingual or multilingual environment of minority areas, the language attitude of language users is more complicated which also makes us think about the multilingual attitude and its factors of college students in the area in order to provide reference for cultivating students' positive multilingual attitude and creating efficient multilingual education in minority areas.

This study analyzes factors on the language attitude from the aspects of gender, grade, major and ethnicity by combining specific language living environment in minority areas to set up correct multilingual values for college students and put forward some suggestions for the cultivation of multilingual talents in minority areas.

\section{LITERATURE REVIEW}

\section{A. Basic Concept}

With regard to language attitude, this study discusses the idea of multilingualism among college students in Yanbian Korean Autonomous Prefecture based on cognitive theory in social psychology. Baker (1992) believed that attitude was a hypothetical construct used to explain the direction and persistence of human behavior. Ajzen (1988) defined attitude as "a disposition to respond favourably or unfavourably to an object, person, institution or event." They both understood that in the case of language, attitude as evaluative reaction towards a specific language, a specific language group (an object) or the activity of learning language (event) and pointed out that language attitude had three components including cognition, affect, and readiness for action.

Domestic multilingualism scholar Wang (1999) believed that people would form a certain understanding or make a certain evaluation of the social value of a language or text because of the influence of social or ethnic identity, emotion, purpose, motivation, behavior tendency and other factors in Chinese bilingual or multilingual society. This kind of cognition and evaluation is usually called language attitude which is divided into emotional attitude and cognitive attitude. Emotional attitude refers to people's emotional experience and feeling of language and cognitive attitude refers

*This research was supported by the research funds of "Research Innovation Project of M.A. Students in Yanbian University" ([2019], No. 20190019 
to people's perception, understanding, belief and evaluation of language. According to Wang's definition of language attitude, the language attitude of college students in minority areas is investigated from the emotional and cognitive dimensions.

\section{B. Research on Language Attitude}

1. Related research at abroad

The research on language attitude abroad has formed a very scientific system from various methodological approaches of measuring language attitude to empirical research which includes both investigation of current situation and the study of factors on language attitude.

Various methodological approaches have been proposed to measure language attitude abroad for evaluating language attitude. The most common instrument to collect data is the questionnaire and the most representative one is Likert scales which is used to find out information about attitudes. Likert (1903) as American educator and psychologist, devised an language attitude scale with five positions ranging from 'totally disagree' to 'totally agree'. Another technique used for the measurement of language attitude is Lambert's (1960) "matched-guise technique". In this case, participants are asked to evaluate the personal qualities of the speakers they hear on a recording with the same speaker using different languages or language varieties. Another technique used is in-depth individual interviews which can provide more detailed information of related areas.

Several studies used questionnaires to measure attitude towards mother tongue and bilingual (multilingual) and analyzed the effect of different factors on language attitude. It is found that students had a positive attitude towards foreign languages and the sociolinguistic context is the most relevant one. Some other educational studies have followed with interest attitude towards L1 at the primary, middle and university level. Cenoz (2001) concluded that learners had more positive attitude towards their L1 and their main language of instruction than other languages, but they also expressed a strong desire to learn a foreign language. According to the several results of studies, it can be indicated that attitude towards multilingualism is in general positive and students wish to learn and speak different languages.

Cenoz (2001)'s "age on language attitude" is the most typical one among the studies of the factors on language attitude. The age on language attitude is a relatively new phenomenon that has received a lot of attention in language education in the last years. Cenoz \& Gallardo (2000) mentioned that children were very happy in the English classes and the early introduction of English language can have a positive effect on attitude. Cenoz (2001) used semantic differentials to compare different school grades and found that attitude towards the three languages were significantly more positive in the case of primary school students than secondary school students. And also included a questionnaire about multilingualism in the study to compare attitudes toward the three languages in three age groups and report significant differences for the total score. Baker (1992) found that attitude towards the minority language became less favorable when age goes up in bilingual settings. It seems that more exposure to English language does not necessarily result in better attitudes. In some cases, it could even happen that more exposure to the language has a negative effect unless learners achieve a basic command of English language, that is, learners may get bored and tired of English classes because their proficiency is still very limited. Therefore, younger learners present more positive attitudes than older learners but this trend is not necessarily maintained in the long run. Gender difference has been obtained on attitudes toward learning several languages. Studies have indicated that females tend to demonstrate significantly more positive attitudes than do males. (Burstall 1975; Gardner \& Smythe 1975; Jones 1950)

2. Related research at home

The domestic research on language attitude is mainly divided into three aspects which provides a reference for domestic related research.

First of all, the survey research of situation on language attitude. Long, et al. (2011) took different students of ethnicities in Xinjiang Normal University as research subjects to investigate the attitude, language choice and language code conversion attitude toward mother tongue and Chinese language in communicative situations by questionnaire. The results showed that students had deep feelings for mother tongue and instrumental factors were larger than emotional factors in their attitude towards Chinese language.

Secondly, the study of factors on language attitude. Yang (2013) investigated the language attitude towards ethnic language, Chinese language and English language of minority college students in Yunnan. The results showed that students had a positive attitude towards three languages with scores of Chinese language, mother tongue and English language in turn, and pointed out that language attitudes were influenced by ethnicity, gender and grade factors. Xia (2012) examined the language attitude and its factors of middle school students in Xishuangbanna area, and found that students had a positive bilingual attitude, female had more positive attitude on the use and study of Chinese language than male, and the Hani minority had more positive attitude on the use and study of Chinese language than the Dai minority. Wei (2012) investigated the language attitude of Zhuang minority college students in Beijing and explored its factors by questionnaire, interview and SPSS statistical analysis. The results showed that the status of mother tongue is lower than that of Chinese language and foreign languages in function and college students are full of enthusiasm for mother tongue in emotion, and found that the state of intermarriage, specialty, gender and code conversion would affect students' language attitude.

Finally, the study on the relevance of language attitude to language competence or achievement. Yan (2013) 
investigated the language attitude of minority college students in Xinjiang and its correlation with language ability by questionnaire and found that students with negative attitude generally had lower English proficiency. Wan (2012) carried out an investigation through questionnaire method and interview to non-English major college students and found that there was a positive correlation between students' English language attitude and achievement .

According to the statements above, the domestic research on language attitude is mainly empirical research and lack of relevant theoretical research. The empirical research has involved various aspects in the research questions, subjects and methods to reflect its diversity. The research question involves the study on the present situation of language attitude, factors and the correlation research; the research subject involves the primary school to the university each stage student and also has the residents and minorities; the research method adopts the questionnaire, interview and the data analysis method and so on.

\section{RESEARCH DESIGN}

\section{A. Research Question}

This study attempts to answer the following questions through investigation.

(1) How about the language attitude of college students in minority areas?

(2) Are there any differences in gender, grade, ethnicity and other factors in the above language attitude?

\section{B. Research Subject}

In this study, a questionnaire survey was conducted from foreign language college of a university in Yanbian Korean Autonomous Prefecture and the multilingual attitudes of 645 college students in minority areas were investigated according to the dimensions of gender, age, major and ethnicity.

\section{Research Method}

First of all, understanding the relevant concepts and theories of language attitude by reading relevant books and materials on academic websites to determine the research questions and prepare for the specific implementation of this study.

Secondly, preparing a suitable questionnaire to college students in minority areas for this study by referring to other scholars' investigation on language attitude and combining with the actual situation in minority areas to investigate the overall situation of the multilingual attitude and analyze the factors of college students' attitude according to each dimension.

\section{RESULTS AND DiSCUSSIONS}

\section{A. Basic Information of Participants}

This study has reviewed the social and psychological factors that affect language attitude through literature research and tried to investigate the multilingual attitudes of college students in minority areas according to the four dimensions of gender, grade, major and ethnicity. The basic information of the participants is shown in Table 1.

TABLE 1 .

BASIC INFORMATION OF PARTICIPANTS

\begin{tabular}{llll}
\hline Dimensions & & Number & Percentage \\
\hline Gender & male & 138 & $21.4 \%$ \\
& female & 507 & $78.6 \%$ \\
Grade & first grade & 261 & $40.47 \%$ \\
& second grade & 165 & $25.58 \%$ \\
& third grade & 133 & $20.62 \%$ \\
Major & fourth grade & 86 & $13.33 \%$ \\
& English & 288 & $44.65 \%$ \\
\multirow{2}{*}{ Ethnicity } & Japanese & 174 & $26.98 \%$ \\
& Russian & 183 & $28.37 \%$ \\
& Han Chinese & 300 & $46.51 \%$ \\
Total & Korean-Chinese & 300 & $46.51 \%$ \\
\hline
\end{tabular}

\section{B. The Overall Multilingual Attitude}

This chapter is to investigate the factors that affect the language attitude of college students in minority areas and first have a comprehensive understanding of the students' overall multilingual attitude which is included pleasant to listen, kindness, usefulness and social influence. 
TABLE 2.

Statistics On LANGUAGe ATtitude (M= AVERAGE, SD= STANDARD DEVIATION)

\begin{tabular}{|c|c|c|c|c|c|c|c|c|c|c|}
\hline \multirow[t]{2}{*}{ Language attitude } & \multicolumn{2}{|c|}{ Chinese } & \multicolumn{2}{|c|}{ Korean } & \multicolumn{2}{|c|}{ English } & \multicolumn{2}{|c|}{ Japanese } & \multicolumn{2}{|c|}{ Russian } \\
\hline & $\mathrm{M}$ & $\mathrm{D}$ & $\mathrm{M}$ & $\mathrm{D}$ & $\mathrm{M}$ & $\mathrm{D}$ & $\mathrm{M}$ & $\mathrm{D}$ & $\mathrm{M}$ & $\mathrm{D}$ \\
\hline $\begin{array}{l}\text { Pleasant to listen } \\
\text { Kindness }\end{array}$ & 4.552 & .762 & 3.595 & 1.420 & 3.975 & 1.079 & 3.553 & 1.390 & 2.977 & 1.484 \\
\hline Usefulness & 4.685 & .668 & 3.298 & 1.492 & 3.549 & 1.092 & 3.107 & 1.340 & 2.419 & 1.414 \\
\hline Social influence & 4.871 & .470 & 3.691 & 1.353 & 4.409 & .987 & 3.617 & 1.304 & 3.076 & 1.525 \\
\hline \multirow[t]{2}{*}{ Total } & 4.840 & .512 & 3.453 & 1.286 & 4.513 & .928 & 3.476 & 1.204 & 3.050 & 1.363 \\
\hline & \multicolumn{2}{|c|}{$\mathrm{M}=18.949$} & \multicolumn{2}{|c|}{$\mathrm{M}=14.037$} & \multicolumn{2}{|c|}{$\mathrm{M}=16.447$} & \multicolumn{2}{|c|}{$\mathrm{M}=13.753$} & \multicolumn{2}{|l|}{11.521} \\
\hline
\end{tabular}

Table 2 shows that the language attitude of college students in minority areas towards five languages are followed by Chinese language $(M=18.949)>$ English language $(M=16.447)>$ Korean language $(M=14.037)>$ Japanese language $(M=13.753)>$ Russian language $(M=11.521)$. It indicates that college students in minority areas hold more positive ideas about the feeling and function of Chinese language, followed by English language and Korean language. On the whole, students' cognitive attitude towards the five languages is more positive than their emotional attitude. Chambers \& Gary N (1999) indicated that pupils felt positive about the target language countries and was motivated more by extrinsic or instrumental factors like getting a certificate or job. It can be seen that the results of this study are obviously consistent with the results of other scholars mentioned above. The reason is that college students are more mature in cognition than primary or middle school students and their attitude and evaluation of language are not limited to emotional factor, but pay more attention to whether language has function and influence.

\section{Factors of Language Attitude}

\section{Gender}

Gender is one of the most basic and universal criteria in sociolinguistic research. Several research results show that females have an advantage over males in language attitudes and abilities through reviewing previous studies on gender attitudes towards language.

TABLE 3

DESCRIPTIVE STATISTICS

\begin{tabular}{llllll}
\hline \multirow{2}{*}{ Chinese } & Gender & $\mathrm{N}$ & Mean & Std. Deviation & Std. Error Mean \\
& Male & 138 & 18.44 & 2.704 & .230 \\
\multirow{3}{*}{ Eorean } & Female & 507 & 19.09 & 1.766 & .078 \\
& Male & 138 & 13.20 & 5.448 & .464 \\
& Female & 507 & 14.27 & 4.708 & .209 \\
\multirow{2}{*}{ Japanese } & Male & 138 & 15.64 & 4.185 & .356 \\
& Female & 507 & 16.66 & 3.101 & .138 \\
Russian & Male & 138 & 13.45 & 4.941 & .421 \\
& Female & 507 & 13.84 & 4.325 & .192 \\
& Male & 138 & 11.25 & 5.181 & .441 \\
& Female & 507 & 11.60 & 4.799 & .213 \\
\hline
\end{tabular}

TABLE 4.

INDEPENDENT SAMPLES TEST

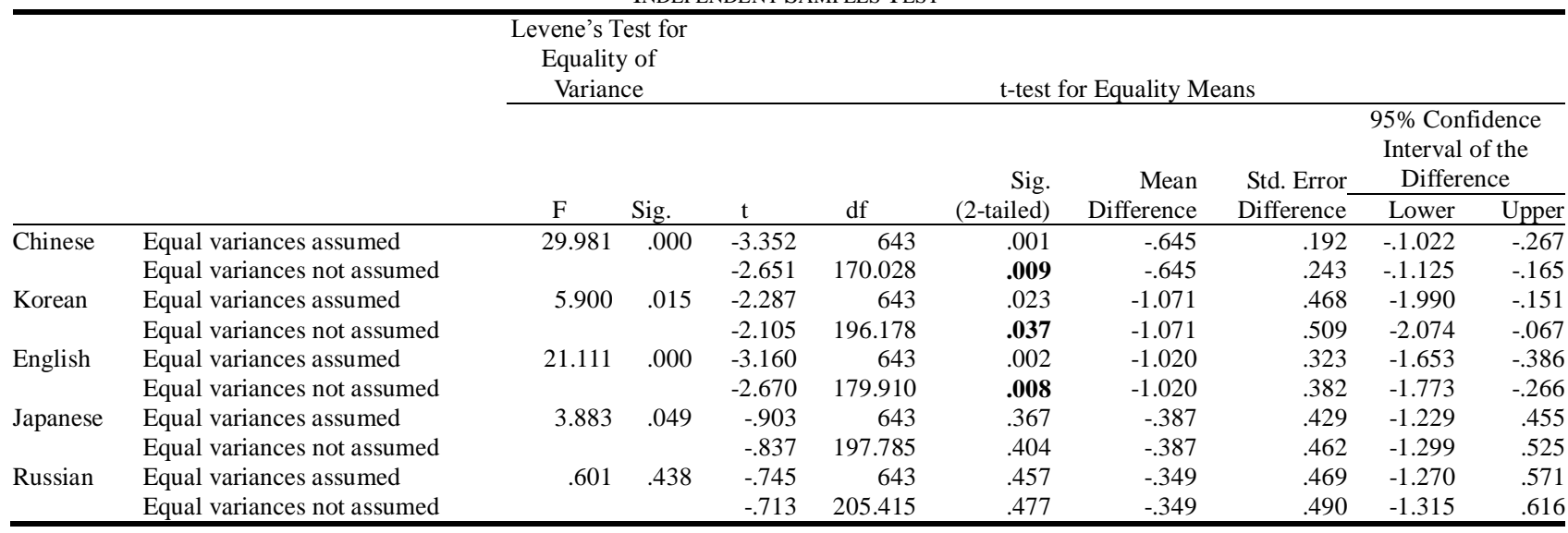

Table 3 shows that males have the lower score than females in the five languages. Females are more tolerant, sensitive and receptive to language, while males are more blunt about language. Both males and females have the highest score in Chinese language with 18.44 and 19.09 respectively. Moreover, females are significantly different from males on the attitudes towards Chinese language, Korean language and English language according to the Table 4. Inspections of two groups means indicate that the average language attitude score of females is significantly higher than the score of males. Females are more receptive to new things, resulting in a strong curiosity about new languages, while 
males are conservative about language according to other relevant research results.

2. Grade

Previous scholars have carried out different studies according to the grade and age stage of the students. Cenoz (2002) compared the language attitude of the students in different age stages and concluded that the students who learned English language in the lower grade showed a more positive attitude than the higher grade, but domestic scholar Chen (2008) drew different conclusions that the students in the higher grade had a more positive language attitude. Cenoz's research is aimed at students from primary to high school, while Chen takes college students as the subjects and it will produce diametrically opposite research results.

TABLE 5.

DESCRIPTIVE STATISTICS

\begin{tabular}{|c|c|c|c|c|c|c|c|c|c|}
\hline \multirow[b]{2}{*}{ Language } & \multirow[b]{2}{*}{ Grade } & \multirow[b]{2}{*}{$\mathrm{N}$} & \multirow[b]{2}{*}{ Mean } & \multirow[b]{2}{*}{ Std. Deviation } & \multirow[b]{2}{*}{ Std. Error } & \multicolumn{2}{|c|}{$95 \%$ Confidence Interval for Mean } & \multirow[b]{2}{*}{ Minimum } & \multirow[b]{2}{*}{ Maximum } \\
\hline & & & & & & Lower Bound & Upper Bound & & \\
\hline \multirow[t]{5}{*}{ Chinese } & First & 261 & 19.08 & 1.741 & .108 & 18.86 & 19.29 & 12 & 20 \\
\hline & Second & 165 & 18.84 & 2.247 & .175 & 18.50 & 19.19 & 4 & 20 \\
\hline & Third & 133 & 19.05 & 1.568 & .136 & 18.78 & 19.32 & 14 & 20 \\
\hline & Fourth & 86 & 18.60 & 2.800 & .302 & 18.00 & 19.21 & 4 & 20 \\
\hline & Total & 645 & 18.95 & 2.019 & .080 & 18.79 & 19.10 & 4 & 20 \\
\hline \multirow[t]{5}{*}{ Korean } & First & 261 & 13.70 & 4.993 & .309 & 13.09 & 14.31 & 4 & 20 \\
\hline & Second & 165 & 13.76 & 5.281 & .411 & 12.95 & 14.58 & 4 & 20 \\
\hline & Third & 133 & 14.41 & 4.586 & .398 & 13.62 & 15.19 & 4 & 20 \\
\hline & Fourth & 86 & 15.02 & 4.104 & .443 & 14.14 & 15.90 & 4 & 20 \\
\hline & Total & 645 & 14.04 & 4.891 & .193 & 13.66 & 14.42 & 4 & 20 \\
\hline \multirow[t]{5}{*}{ English } & First & 261 & 16.52 & 3.324 & .206 & 16.11 & 16.92 & 4 & 20 \\
\hline & Second & 165 & 16.33 & 3.431 & .267 & 15.81 & 16.86 & 4 & 20 \\
\hline & Third & 133 & 16.65 & 3.097 & .269 & 16.12 & 17.18 & 4 & 20 \\
\hline & Fourth & 86 & 16.14 & 3.896 & .420 & 15.30 & 16.97 & 4 & 20 \\
\hline & Total & 645 & 16.45 & 3.385 & .133 & 16.18 & 16.71 & 4 & 20 \\
\hline \multirow[t]{5}{*}{ Japanese } & First & 261 & 13.98 & 4.557 & .282 & 13.42 & 14.53 & 4 & 20 \\
\hline & Second & 165 & 13.36 & 4.664 & .363 & 12.64 & 14.07 & 4 & 20 \\
\hline & Third & 133 & 13.44 & 4.118 & .357 & 12.73 & 14.14 & 4 & 20 \\
\hline & Fourth & 86 & 14.33 & 4.255 & .459 & 13.41 & 15.24 & 4 & 20 \\
\hline & Total & 645 & 13.75 & 4.463 & .176 & 13.41 & 14.10 & 4 & 20 \\
\hline \multirow[t]{5}{*}{ Russian } & First & 261 & 11.80 & 5.150 & .319 & 11.17 & 12.43 & 4 & 20 \\
\hline & Second & 165 & 11.00 & 4.978 & .388 & 10.23 & 11.77 & 4 & 20 \\
\hline & Third & 133 & 11.71 & 4.224 & .366 & 10.98 & 12.43 & 4 & 20 \\
\hline & Fourth & 86 & 11.38 & 4.797 & .517 & 10.36 & 12.41 & 4 & 20 \\
\hline & Total & 645 & 11.52 & 4.881 & .192 & 11.14 & 11.90 & 4 & 20 \\
\hline
\end{tabular}

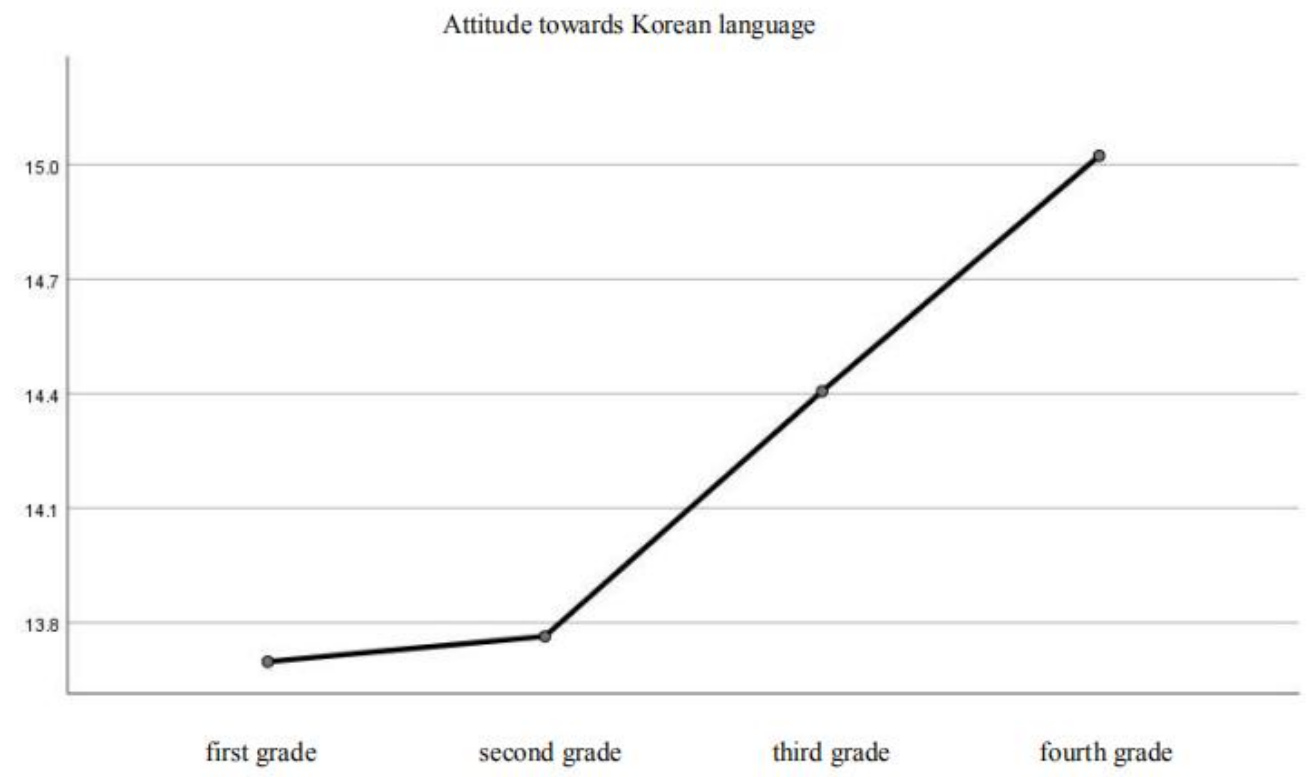

Figure 1. Comparison of grades on Korean language attitude 


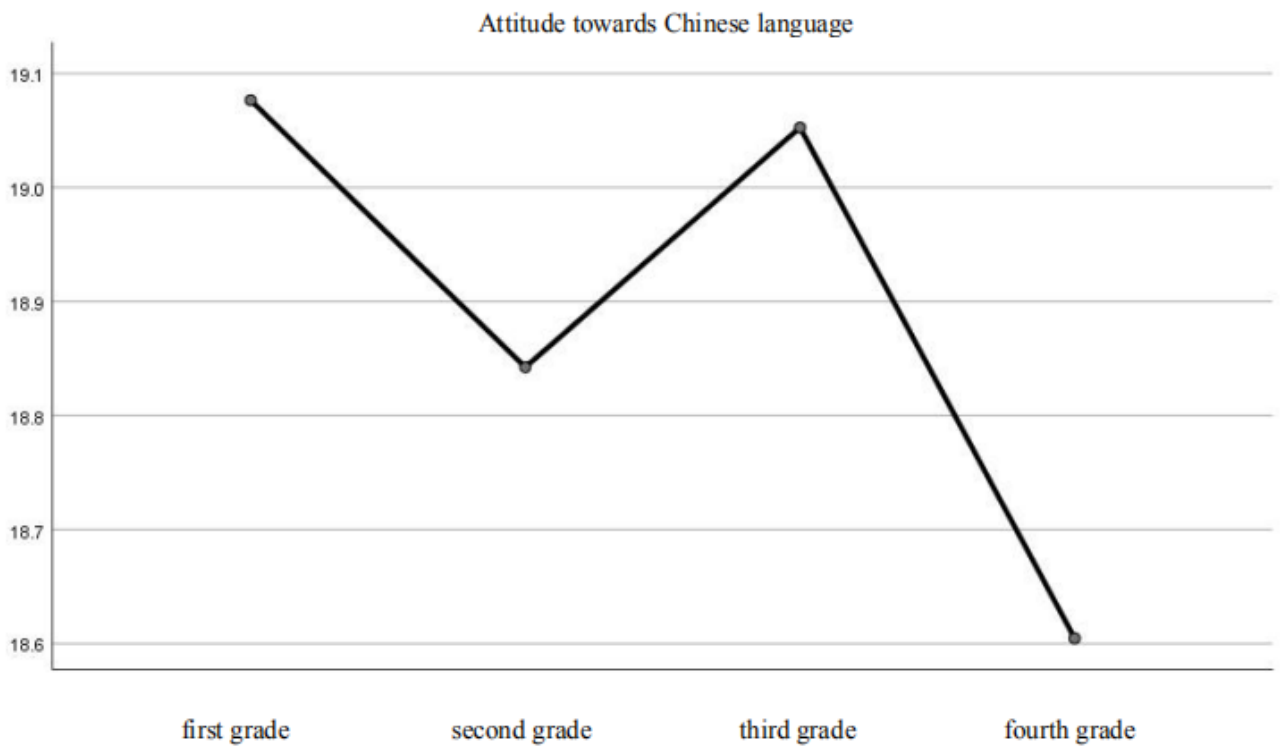

Figure 2. Comparison of grades on Chinese language attitude

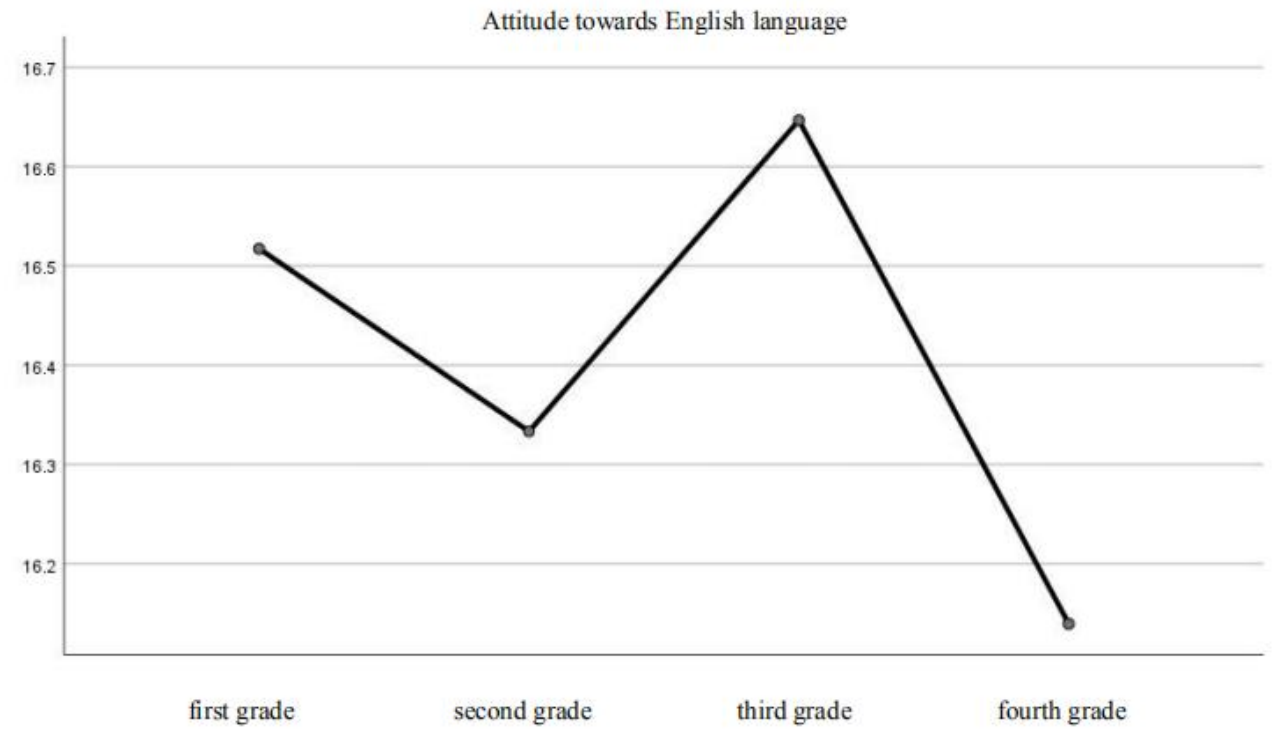

Figure 3. Comparison of grades on English language attitude 


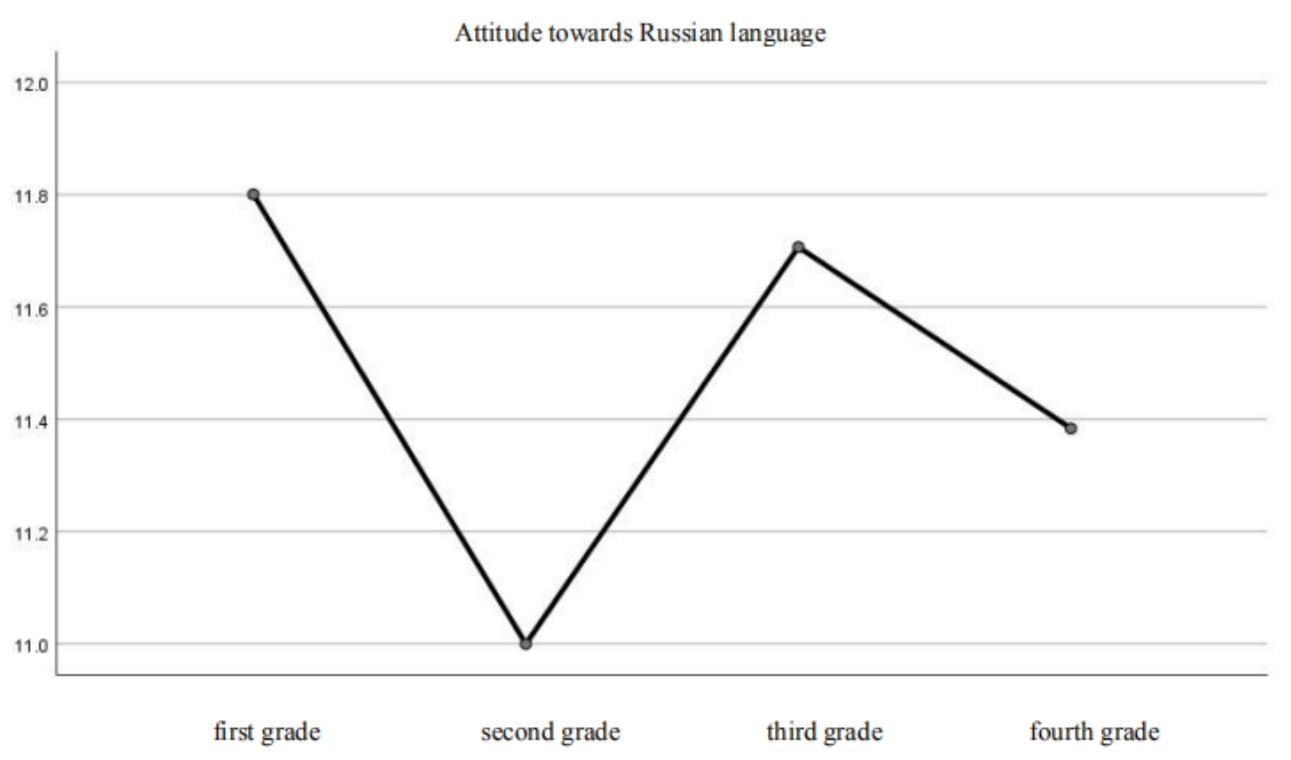

Figure 4. Comparison of grades on Russian language attitude

As shown in Table 5, students with four different grades do not show significant differences in attitude towards the five languages, but there are still some parts worth exploring. According to Fig. 1, we can see that the attitude towards Korean language increases from 13.70 points to 15.02 points to show a trend of sustained growth. It can be seen that environment in the gathering area of Korean Autonomous Prefecture has an impact on students' language attitude. With the increase of students' living time in this environment, attitude towards Korean language shows an upward trend. The attitude of students towards Chinese language is decreasing with the increase of grade. From the Fig. 2, Chinese language attitude of the students on the fourth grade is 18.60 points, while that of first grade is 19.08 points. It can be indicated that with the learning of other foreign languages, the interest in the native language gradually declined. It is worth paying attention to the attitude towards English language and Russian language, and it shows the same trend as is shown in Fig. 3 \& 4. The scores of first grade are higher, the second grade shows a downward trend and from the third grade gradually shows a trend of growth to the fourth grade. And it is obviously similar to the above research results of Cenoz and Chen scholar. According to Cenoz's research, attitude towards languages were significantly more positive in the case of junior students than senior students and students are very curious about the early introduction of new foreign languages. The reason is that learners may get bored and tired of learning languages because their proficiency is still very limited. Therefore, younger learners present more positive than older learners but this trend is not necessarily maintained in the long run. In addition, first grade students have a deeper curiosity about foreign languages and culture at the beginning of school, but in the second grade because of the difficulty of language learning and the burden of strengthening the ability to reduce the enthusiasm for foreign languages, by the end of graduation begins to plan career and life to understand the importance of foreign language learning which promotes the acceptance of foreign languages to increase. In general, the attitude of students toward language does not appear the trend of continuous growth or decrease with the increase of grade but presents a more complex phenomenon of fluctuation which reflects the psychological changes of students in different stages.

\section{Major}

Students in different language majors will have different scores in each language attitude especially between their mother tongues, languages of their own majors and other foreign languages.

TABLE 6.

COMPARISON OF MAJORS ON LANGUAGE ATTITUDE

\begin{tabular}{|c|c|c|c|c|c|c|c|c|}
\hline & \multicolumn{2}{|c|}{$\begin{array}{l}\text { Major in English } \\
(\mathrm{n}=288)\end{array}$} & \multicolumn{2}{|c|}{$\begin{array}{l}\text { Major in Japanese } \\
(\mathrm{n}=174)\end{array}$} & \multicolumn{2}{|c|}{$\begin{array}{l}\text { Major in Russian } \\
(\mathrm{n}=183)\end{array}$} & \multirow[t]{2}{*}{$\begin{array}{l}F \\
(2,642)\end{array}$} & \multirow[t]{2}{*}{$\begin{array}{l}\text { Post Hoc } \\
\text { (Tukey) }\end{array}$} \\
\hline & $\mathrm{M}$ & SD & $\mathrm{M}$ & SD & $\mathrm{M}$ & SD & & \\
\hline Chinese & 18.91 & 1.92 & 18.73 & 2.39 & 19.22 & 1.76 & 2.73 & \\
\hline Korean & 13.95 & 4.88 & 14.30 & 4.80 & 13.91 & 5.01 & .360 & \\
\hline English & 16.81 & 3.08 & 15.96 & 3.46 & 16.33 & 3.71 & 3.61 & Major in English > Japanese \\
\hline Japanese & 13.34 & 4.34 & 16.07 & 3.30 & 12.19 & 4.75 & $40.36^{*}$ & $\begin{array}{l}\text { Major in Japanese }>\text { English } \\
\text { Major in Japanese }>\text { Russian }\end{array}$ \\
\hline Russian & 9.82 & 4.41 & 10.49 & 4.51 & 15.17 & 3.92 & $93.11^{*}$ & $\begin{array}{l}\text { Major in Russian > English } \\
\text { Major in Russian }>\text { Japanese }\end{array}$ \\
\hline
\end{tabular}

$* p<0.05$

Table 6 shows that the scores of three majors on attitude towards Chinese language $(M=18.91,18.73,19.22)$ is the 
highest of five languages. And there is no significant difference in Korean language attitude between students of three majors. Students majoring in Japanese have the balanced scores on five languages than students majoring in English and Russian including Korean language $(M=14.30)$, English language $(M=15.96)$, Japanese language $(M=16.07)$ and Russian language $(\mathrm{M}=10.49)$. But the score of attitude toward Chinese language presents the lowest score with 18.73 points. Students majoring in Japanese language have a deeper understanding of foreign language culture with the longer time of foreign language learning and the level of foreign language improves to a certain extent which promotes the acceptance of foreign languages to reduce enthusiasm for the mother tongue. Therefore, it is necessary to strengthen the teaching of Chinese language for those who major in Japanese and enhance the sense of belonging to their mother tongue. What's more, each of the three major students have the highest score on language attitudes of their own majors, with English language $(M=16.81)$, Japanese language $(M=16.07)$ and Russian language $(M=15.17)$ respectively and the scores are significantly different from those of other two majors. The score of attitude toward Russian language is significantly varied by the majors $(F(2,642)=93.11, p<0.05)$. Tukey's post hoc procedure indicates that those who major in Russian language are significantly more positive about Russian language than other two majors. There is not a significant difference in score of Russian language attitude between those who major in English and Japanese, and this phenomenon also appears in Japanese language attitude. It indicates that students have a longer and more in-depth study of their own major than students majoring in other languages which promotes a positive and open attitude towards language of their own majors.

4. Ethnicity

Ethnicity identity is also a factor worth exploring because of the characteristics on specific ethnic minorities in China. This chapter will focus on the different ethnicities of attitudes toward mother tongues, the official language of the country and other foreign languages.

TABLE 7.

COMPARISON OF ETHNICITIES ON LANGUAGE ATTITUDE

\begin{tabular}{|c|c|c|c|c|c|c|c|c|}
\hline \multirow[b]{3}{*}{ Chinese } & \multicolumn{2}{|c|}{$\begin{array}{l}\text { Han Chinese } \\
(\mathrm{n}=300)\end{array}$} & \multicolumn{2}{|c|}{$\begin{array}{l}\text { Korean-Chinese } \\
(\mathrm{n}=300)\end{array}$} & \multicolumn{2}{|c|}{$\begin{array}{l}\text { Other minorities } \\
(\mathrm{n}=45)\end{array}$} & \multirow{2}{*}{$\begin{array}{l}F \\
(2,642)\end{array}$} & \multirow[t]{2}{*}{$\begin{array}{l}\text { Post Hoc } \\
\text { (Tukey) }\end{array}$} \\
\hline & $\mathrm{M}$ & SD & $\mathrm{M}$ & SD & $\mathrm{M}$ & SD & & \\
\hline & 19.41 & 1.60 & 18.46 & 2.21 & 19.18 & 2.46 & $17.80 *$ & $\begin{array}{l}\text { Han Chinese > Korean-Chinese } \\
\text { Other minorities > Korean-Chinese }\end{array}$ \\
\hline Korean & 11.86 & 4.89 & 16.62 & 3.35 & 11.36 & 5.17 & $102.96 *$ & $\begin{array}{l}\text { Korean-Chinese }>\text { Han Chinese } \\
\text { Korean-Chinese }>\text { Other minorities }\end{array}$ \\
\hline English & 16.72 & 3.45 & 16.22 & 3.17 & 16.16 & 4.21 & 1.80 & \\
\hline Japanese & 13.11 & 4.80 & 14.44 & 3.90 & 13.47 & 5.08 & 6.96 & \\
\hline Russian & 12.24 & 4.95 & 10.76 & 4.70 & 11.84 & 4.96 & 7.14 & \\
\hline
\end{tabular}

As shown in Table 7, Han Chinese students have the highest score $(M=19.41)$ for the attitude of Chinese language, while Korean-Chinese students have the lowest score $(M=18.46)$. The scores of attitude towards Korean language are significantly varied by the ethnicities $(F(2,642)=102.96, p<0.05)$. Tukey's post hoc procedure indicates that Korean-Chinese students are significantly more positive about Korean language than Han Chinese and other minorities. There is not a significant difference in the scores of attitude toward Korean language between Han Chinese and other minorities and this phenomenon also appears in Chinese language attitude. It is obviously that the attitudes of students towards their mother tongues are more positive than that of other ethnicities and both Han Chinese and Korean-Chinese students have a positive attitude towards their mother tongue. Han Chinese and other minorities give higher scores to English as a foreign language in addition to their own language ( $M=16.72,16.16)$, while the Korean-Chinese students have a more positive attitude toward Japanese language $(\mathrm{M}=14.44)$. Han Chinese and Korean-Chinese students present the basic similar high scores in each language attitude but there is not significant difference on the scores of Korean-Chinese. It can be concluded that the Korean-Chinese students have a high acceptance of foreign languages relative to Han Chinese and other minorities. Compared with the Han Chinese students who only learn Chinese language and English language, Korean-Chinese students are open to foreign languages who live in a multilingual environment from an early age and receive a multilingual education. However, other minorities students have a lower score on attitude towards foreign languages than Han Chinese and Korean-Chinese students and teachers should strengthen guidance to these students.

\section{CONCLUSION AND IMPLICATION}

\section{A. Major Findings}

College students in minority areas have a positive attitude towards the functions and development prospects of Chinese, Korean, English, Japanese and Russian languages, but the degree of Chinese language is the highest, followed by English language and Korean language. In terms of gender, females show more positive language attitudes than males especially in Chinese, English and Korean language; in terms of grades, attitude toward Korean language tends to increase as grades increase, while other languages decrease as grades increase, but this trend is not maintained in the long run; in terms of major, students in three majors have the highest score on language attitude of their own major; and 
in terms of ethnicity, both Han Chinese and Korean-Chinese students have the highest attitude scores toward their mother tongues and Korean-Chinese students are more receptive to foreign languages than other minorities students.

\section{B. Implication}

The multilingual attitudes of different students are complex and diverse. Schools should respect individual differences of students and consider the environmental factors of students' language background to make students treat each language correctly and form correct multilingual values, and lay a solid foundation for better multilingual education in minority areas.

Teachers can select topics of interest to males when teaching foreign languages to enhance the attention and motivation of learning and make more students learn foreign languages in a pleasant teaching environment. And for females who are easy to accept new foreign languages, teachers should emphasize the importance of mother tongue learning and establish a strong sense of identity and pride in mother tongue. Teachers should understand the different language attitudes and ideas of students and organize teaching activities to meet different language learning needs and cultivate the ability of autonomous learning, and achieve better teaching outcomes.

Teachers can strengthen the guidance of students in different grades and majors to help students reflect on the differences of cultures and languages. Teachers can encourage the study of foreign languages and understand foreign culture for the second grade students to stimulate interest in foreign language learning and treat their mother tongue correctly, and achieve the effect on mutual promotion of mother tongue and foreign languages for senior students. For students with different majors, teachers can strive to improve teaching methods so that students do not lose interest in their own majors and improve their language proficiency, and strengthen the level of mother tongue and increase the opportunities for learning in mother tongue at the same time. The syllabus of English majors in universities (2000) pointed out that students of English majors should cultivate the ability of cross-cultural communication and pay attention to the education of patriotism and collectivism. Therefore, foreign language teachers should also help students understand their mother tongue while teaching foreign languages.

For Korean-Chinese students, teachers can strengthen the guidance of Korean language while not reducing their interest in language learning, and form better critical thinking to help students recognize and understand other languages objectively; for Han Chinese students, teachers should give correct guidance and effective support in teaching methods so as to maintain the functionality of foreign languages and the superiority of Chinese. Chinese is a language that students must master in their lifelong learning, survival and development. However, due to the majority of Korean-Chinese students in the region from childhood to Korean-Chinese schools, subjects are mainly teaching in Korean language so that Korean-Chinese students' Chinese language ability is weaker than Han Chinese students. Compared with Han Chinese students, Korean-Chinese students are hard to ensure that they keep a clear mind about their mother tongue while touching other cultures.

In conclusion, multilingual education in minority areas should provide efficient multilingual courses according to students' language needs and choice. Due to the factors of gender, grade, major and ethnicity, there are some differences in college students' attitudes towards each language. Therefore, schools should attach importance to the attitude and ideas of each student to provide multilingual education models on the basis of respecting students' willingness, such as providing multilingual learning courses with different combinations, encouraging Han Chinese students to take courses in minority culture and language so as to meet students' diverse language learning needs and improve students' multilingual skills, and contribute to the cultivation of diversified language talents in the new period.

\section{REFERENCES}

[1] Ajzen, I. (1988). Attitudes, personality and behavior. Chicago, IL: Dorsey Press.

[2] Baker, C. (1992). Attitudes and language. Clevedon: Multilingual Matters.

[3] Burstall, C. (1975). French in the primary school: the British experiment. Canadian Modern Language Review 31, 388-402.

[4] Cenoz, J \& Gallardo, F. (2000). Evaluation del proyecto de plurilinguismo. Unpublished research report.

[5] Cenoz, J. (2009). Towards multilingual education. United States: St Nicholas House.

[6] Chen Xinren. (2008). Foreign language education and national identity in the context of globalization. Beijing: Higher Education Press.

[7] Chamber \& Gary, N. (1999). Motivating language learners. England: Multilingual Matters.

[8] English group of College English Teaching Steering Committee. (2000). English teaching syllabus for English majors in higher education. Shanghai: Shanghai Foreign Language Education Press.

[9] Gardner, R. C. (1985). Social psychology and second language learning. London: Edward Arnold Publisher.

[10] Gardner, R. C \& Smythe, P. C. (1975). Motivation and second language acquisition. The Canadian Modern Language Review 31, 218-30.

[11] Jones, W. R. (1950). Attitudes towards Welsh as a second language: a preliminary investigation. British Journal of Educational Psychology 20, 117-32.

[12] Long Y., Malihaba A., \& Zhang B. (2011). Urvey in language-learning manner of Uygur college students with ethnic. Journal of Xinjiang Normal University (Social Sciences) 6, 102-108.

[13] Wan Qinglin. (2012). A correlative study of non-English majors' English attitudes and their English achievements. Journal of Shayang Teachers College 5, 48-51.

[14] Wang Yuanxin. (1999). Several problems on the attitude of minority languages in China. Manchu Studies 1, 87-99. 
[15] Wei Lin. (2012). A Survey of Language Use and Attitude of Zhuang Ethnicity College Students in Beijing. Master's dissertation, Minzu University of China.

[16] Xia Wei. (2012). A survey study of language use and attitude of middle school students in Xishuangbanna minority area. Master's dissertation, East China Normal University.

[17] Yan Xinyan. (2013). Investigation of Xinjiang Kazak college students' language attitudes and ability of Kazak language, Chinese and English. Journal of Yili Normal University (Social Science Edition) 3, 17-21.

[18] Yang Yu. (2013). Research on ethnic identity and language attitudes of minority college students in Yunnan. Ph.D. dissertation, Shanghai International Studies University.

Yujie Shi, born in Jilin Province, China in 1994. She is an M.A. student majoring in English education in Yanbian University.

Xuebo Cui is the corresponding author. She was born in Yanji, China. She received PH.D. degree in Applied Linguistics from De La Salle University, Manila in the Philippines in 2004.

She is currently an associate professor in English Department, Yanbian University, China. Her research interests include curriculum design and development, professional development for teachers of English, bilingual education, and contrastive linguistics. 